\title{
CURIOSITY OF PAY-PER-BID AUCTIONS: EVIDENCE FROM BONUS.CZ AUCTION SITE
}

\author{
Miroslav Svoboda, Petr Bocák*
}

\begin{abstract}
:
This paper analyses the pay-per-bid auctions which have appeared recently on the Internet and scored an immediate business success. In these auctions bidders pay a small, but irrevocable fee each time they want to increase the price. In this paper we test the model suggested by Platt, Price and Tappen (2010), which forecasts the distribution of closing prices depending on the item's value, bid fee and price increment. The data from the Czech leading auction site Bonus.cz were chosen for the test. Observed closing prices distribution of about $69 \%$ of commonly auctioned items fits the model. However, we find some theoretical and practical flaws in the model. Contrary to the model predictions, we observed that auctions with smaller price increments generated significantly higher revenue than auctions with higher price increments. We suggest that bidders who favour skewness in payoff distribution cause auctions with lower price increment run longer and therefore explain this discrepancy.
\end{abstract}

Keywords: auction theory, pay-per-bid auction, auction modelling, risk, skewness.

JEL Classification: C12, C51, D44, L81, L83

\section{Introduction}

In 2005, a new auction format was invented, when the German company $\mathrm{Swoopo}^{1}$ came up with not only an online version of the standard auction. It started a pay-per-bid auction ${ }^{2}$ where bidders paid a small and irrevocable fee each time they wanted to increase the price. The closing price was usually very low, and thus very attractive. Unlike on Ebay, Swoopo sells only brand new goods. Users cannot sell their unnecessary stuff, they can only bid. This auction model scored huge success, so it did not take long for a pay-per-bid auction site to appear in the Czech Republic. The first amateur attempts occurred in late 2008. In the second half of 2009 Bonus.cz started its business and quickly became the leader in pay-per-bid auctions in the Czech Republic.

Every auction on Bonus.cz starts at an initial price zero and the current price increases by a predetermined amount with each bid and increases the time on the countdown clock

\footnotetext{
* University of Economics, Prague, nám. W. Churchilla 4, 13067 Praha 3 (miroslav.svoboda@vse.cz).

1 Swoopo was the world leader in pay-per-bid auctions, but the site is currently down and the company running it filed for bankruptcy.

2 Pay-per-bid auctions are also known as penny auctions or pay-to-bid auctions.
} 
by up to 30 seconds. With each bid a fee is deducted from the customer's account. When time expires, an auction ends and the highest bidder is entitled to buy the item for the final price.

Potential bidders are attracted to Bonus.cz for televisions, computers, cell phones and many more items at extremely low prices. Such offers are possible only because most of the collected revenue comes from bidding fees. To be profitable, it is sufficient for the final price to reach only $16 \%$ of suggested retail price (SRP) for auctions that increase by CZK $1^{3}$, and only $1.9 \%$ for auctions that increase by CZK 0.1 . In fact, the average closing price among all CZK 0.1 auctions is around $2.4 \%$ and for CZK 1 auctions it is $15.3 \%$. In addition, low sale prices compared to real values reduce costs for Bonus.cz. Whereas many retailers suffer additional costs from credit card charge backs and returns, low sale price virtually eliminates these costs, since it cannot cover transaction costs tied with a return (on customers' side). With pay-per-bid auctions, almost all money of a consumer is spent on bids and from a legal point of view these are not a part of the sale price of the won item.

Some authors claim that this selling scheme considerably resembles a lottery in fact. Each bid may be considered as a lottery ticket, with a low price, bought by many participants, in order for one to win a valuable item for a small fraction of its worth (Augenblick, 2009). On the other hand, every time a leader is outbid, his previous bids have no bearing on future probabilities of winning. Non-winning bids could be considered as sunk cost. It would be more appropriate to describe such a mechanism as a game rather than an auction. Bonus.cz uses strictly the term "auction" to avoid regulation by local lottery laws (Zandl, 2009).

The concept of pay-per-bid auctions is closely related to commonly known all-pay auctions, where also during an auction all (or at least two) bidders incur costs that are not compensated. The one, who spends the most resources, becomes a winner. Baye et al. (1996) gives a description of all Nash equilibriums for first-price all-pay auctions with full information, which are commonly used for modelling rent-seeking, technological research, campaigning, or job-promotion. Second-price all-pay auctions are commonly called "war of attrition". J. M. Smith (1974) was first to introduce this concept. War of attrition is commonly used for modelling contests between animals, bargaining, and industrial competition.

Pay-per-bid auctions are similar to the famous "dollar auction" game created by Shubik (1971), where the winner receives the auctioned item for his winning bid but the secondhighest bidder also pays his bid to the auctioneer. Shubik wrote that in such an auction "bidding could never cease"; as the two highest bidders are stuck in an endless and exhausting fight for cost-minimization. At each point, the second highest bid is sunk (will be paid regardless of the result); therefore, the bidder weighs only his bid-increment against $\$ 1$, which he gets if no other bid occurs. By contrast, in a pay-per-bid auction,

CZK 1 is about USD 0.05 . 
the winner does not get the prize - he only gets the right to buy it. If the price of the item increases with every bid, a pay-per-bid auction for one dollar should stop at $\$ 1$ reduced by the cost of one bid. (After this point, any bid would ensure a victory to a bidder but incur a loss at the same time.) Pay-per-bid auction operators compensate for such a strict limit in bidding by setting a very low predetermined price increment. Thus, it is difficult for any pay-per-bid auction to come close to its limit even when the value is quite low, but it is virtually impossible for high-ticket items. Some pay-per-bid auctions use a zero price increment; then the resemblance to a dollar auction is even stronger. Still, a key difference remains: The winner of a pay-per-bid auction does not necessarily need to participate from the beginning or spend the most resources (in fact, quite the opposite is usual). Anyone at any time can join in the auction and, therefore, they do not bear the costs of previous bids.

Only a few papers have recently appeared on pay-per-bid auctions. Platt et al. (2010) developed a model predicting a particular distribution of closing prices which they tested against the data collected from Swoopo auction site. Their model posited symmetry among potential bidders in each period of an auction, and fit the data robustly, especially when allowed for risk preference. Augenblick (2009) started with a similar symmetric model, but moved further; compared to Platt et al. (2010) who collected only auction level data, he succeeded in collecting individual-bids data from thousands of auctions which made it possible to analyse the subject deeper. He observed that pay-per-bid auctions not only yield bigger revenues than is predicted by a symmetric model with risk-neutral agents, but that also overbidding becomes stronger as the action proceeds. Such a phenomenon couldn't be explained by risk preference only, and Augenblick (2009) resolves it by incorporating a sunk cost fallacy into his model. Moreover, he discusses the supply side of the pay-per-bid auction business, calculating the relationship between number of active bidders and optimal number of active auctions. Thus he explains why there are large barriers to entry, even though it is extremely cheap to run a new auction site.

Hinnosaar (2010) drew up a thorough game-theoretic analysis of pay-per-bid auctions. As the above mentioned authors, he also concentrates on a model with symmetry among potential bidders. But then, Byers et al. (2010) included asymmetry in the explanation. They prove that high profit margin of pay-per-bid auctions can be explained even if not allowed for risk preference or sunk cost fallacy. The sufficient condition is users' asymmetric situation (such as erroneous assessment of real number of active auction participants, different valuations of items, better estimates of other players' behaviour etc.).

In our paper we use the model suggested by Platt, Price and Tappen (2010) that describes choices made by potential bidders in symmetric sub-game perfect Nash equilibrium. A total of more than 6,000 auctioned items were collected and divided by article and bid increment into 130 subsets. Then we compared predicted and observed distributions of 
closing prices and for about $69 \%^{4}$ of regularly auctioned items the distribution of closing prices is not in conflict with the predicted distribution at $5 \%$ significance level.

However, we question the relevance of the model as for practical purposes which potential bidders or pay-per-bid auctions site owners might be interested in. The model predicts that the revenue generated by auctions does not depend on the level of price increment used. By contrast, we find that on average, auctions with a price increment CZK 0.1 generate about $30 \%$ economic profit while auctions with a price increment CZK1 deliver a slight loss.

The paper is organized as follows: Section 2 gives a brief overview of the model suggested by Platt et al. that we use for our analysis. In Section 3, we describe our data set collected from Bonus.cz. Section 4 contains results of Chi-square goodness-of-fit test that we performed using our observed data and theoretical distributions. In Section 5, we explore pay-per-bid auctions further; in particular, we test how the collected revenue from observed auctions matches the predictions of the model. Section 6 concludes.

\section{Symmetric Model for Pay-per-Bid Auctions}

In our paper, we utilize the symmetric pay-per-bid auction model that was suggested by Platt et al. (2010). The model predicts the probability that a pay-per-bid auction ends at any given number of bids based on certain intrinsic characteristics of each specific auction.

An auction is offered by the auctioneer at the initial price of CZK0. The auctioned item has a common value $v$ CZK to every bidder. With each bid, the bidder pays a fee of $b$ CZK, the current price is increased by $s \mathrm{CZK}$, the time left is extended by 30 seconds and a new period starts. The auction is terminated when the countdown reaches zero, and the purchased item is shipped to the winner for free.

Every potential bidder is risk-neutral and has to make a decision in each period whether to bid or not. When he decides to place a bid, he in fact bets $b$ CZK that nobody places another bid. When a potential bidder is considering whether to place the $q^{\text {th }}$ bid at the price $s \cdot(q-1) \mathrm{CZK}$, he is facing a decision between certain $b$ CZK if he abstains from bidding and an expected return $(v-s \cdot q) \cdot\left(1-\mu_{q+1}\right)$, where $\mu_{q+1}$ represents the probability that anyone places the $q+1^{\text {th }}$ bid in the next period. The potential bidder compares these figures, chooses the outcome with a higher expected return and acts accordingly.

There is a limit as to the number of bids that any set of rational bidders would place on an auction in total. While not common, an auction can occasionally approach the limit (in case of items with low value and a high price increment). In general, when the number of placed bids is equal to $Q$, where $Q$ is defined as $(v-b) / s$, the sum of the current price and a bid fee is larger than or equal to the value of the auctioned item $v$. The potential bidders

4 This share was obtained by weighing the share of subsets by the number of observed auctions in each subset. 
will not place any more bids irrespective of $\mu_{q_{+1}}$ probability. The highest current price of an auctioned item is then $p=v-b$. Therefore, for every $q \geq Q$, the probability of the next bid is $\mu_{q}=0$. When $q=Q$, all potential bidders must be indifferent about bidding even though $\mu_{q+1}=0$, and the next bidder would always win.

Let us look at an example with a very common auction for 50 bids. It has a common value of CZK 400, since it can be easily obtained from the auctioneer at this price at any time. Every bid costs CZK 8 and increases the current price by CZK 1 . In this case, $Q=392$. Suppose that already 392 bids have been placed, then $\mu_{393}=0$, because a potential bidder would be choosing between certain CZK 8 if he does not bid and $(400-393 * 1) *(1-0)=$ CZK 7 if he places a bid. Therefore, nobody would bid and the auction would terminate. One bid earlier, $\mu_{392}=0$, because a potential bidder would be choosing between certain CZK 8 and $(400-392 * 1) *(1-0)=$ CZK 8 if he bids. The 392th bidder will certainly win this auction, but he is indifferent about bidding since both paths lead to the same payoff.

Moreover, all bidders must be indifferent about bidding in all periods. If $q^{\text {th }}$ bidder would strictly prefer bidding, so $\mu_{q}=1$, then $q-1^{\text {th }}$ bidder would prefer not to bid, and vice versa. When we place an expected return of bidding equal to the bid fee, we obtain the indifference condition. This indifference condition describes specific probabilities, which in this model define equilibrium behaviour of all potential bidders. For every $q$ that satisfies $1<q<Q$, the unique probability that anyone will place a $q^{\text {th }}$ bid is

$$
\mu_{q}=1-\frac{b}{v-s(q-1)} .
$$

Only the probability of the first bid is non-unique. For simplicity and consistency, we follow Platt et al. (2010) and set it $\mu_{1}=1-b / v$. To forecast the probability that an auction ends at any given number of bids, the probability density function from the indifference condition can be derived:

$$
f(q)=\left(1-\mu_{q+1}\right) \prod_{j=1}^{q} \mu_{j}=\frac{b}{v-s \cdot q} \prod_{j=1}^{q}\left(1-\frac{b}{v-s \cdot(j-1)}\right) .
$$

In fact, the probability density function consists of two distinct parts, the probability that $q$ bids have already been placed and the probability that nobody places the next bid. This function is decreasing in the number of bids. That means that there should be more auctions closing in the early stages of an auction, than in later ones. To put it differently, the longer time duration (or, more precisely, bid duration), the less auctions we should see ending.

It also means that not every auction is profitable. Since there are many auctions closing early, there are many auctions incurring loss to an auctioneer as well. However, the loss should be outweighed by the highly profitable long auctions. Average expected revenue could be derived from the probability density function. For pay-per-bid auctions with a non-zero price increment, Platt et al. (2010) calculated the expected revenue to be 
equal to $v-b$, i.e. only slightly less than bidders' valuation. ${ }^{5}$ This formula suggests that the expected revenue from an auction is independent of its price increment. We can also see that selling items using pay-per-bid auctions should generate almost the same revenue as retailing, supposing the same demand. (We question these implications is Section 5.)

\section{Collected Data Set}

From its inception in 2009 till the end of 2010 more than 24,000 auctions took place at Bonus.cz. There were hundreds of different items auctioned but only a handful repeated frequently. 50-bid and 400-bid packs were among the most commonly auctioned items. In our analysis, we chose to include only items that were auctioned at least 50 times. We collected data of 71 different items in over 6,000 auctions that ran from July 2009 till the end of February 2010.

Information about all ended auctions is publicly available at Bonus.cz website. For each auction, its final price, suggested retail price, the price increment, the time of termination, and the list of the last ten bids are indicated. At that time, auctions on Bonus.cz were listed with two different price increments, about $53 \%$ of collected auctions increased by CZK0.1 and the rest increased by CZK1. All auctions used 30-seconds soft end (every placed bid was postponing the end by up to 30 seconds). ${ }^{6}$

Since only the last ten bids are recorded, we could not observe the entire auction. In its Help section, Bonus.cz suggests deriving a number of active bidders from the mentioned list, but we find this measure inappropriate. Many bidders take "observing" breaks during an auction, especially when an aggressive bidder comes forward, to come back right after he quits. Moreover, it is not unusual that there are more than ten bidders at the same time.

We also examined the suggested retail prices, since there was a possibility that they would be deliberately above the average e-shop prices. However, the comparison with the help of the Heureka.cz site showed that the suggested retail prices (SRP) roughly equal prices of online retailers. ${ }^{7}$ Therefore, we consider SRPs as a good measure of potential bidders' valuation of auctioned items.

Pay-per-bid auctions are characterized by high variability in closing prices and duration. Out of 6,000 auctions 88 of them terminated within the first 10 bids and almost $25 \%$ of

5 We can come to the result by simple logic too. Let us start with the situation when the first bid has already been placed. Note that at each moment, participants must be indifferent as for bidding, i.e. their expected gain is null. Then, if the item of value $v$ is handed to one of them at the end of the auction, the value $v$ must also be the financial amount collected during the auction (bids + closing price).

If we account for the fact that the probability of the first bid is smaller than 1 , the collected revenue is smaller than $v$. In our case, it is $v \cdot(1-b / v)=v-b$.

6 Later, Bonus.cz started to offer also a "sprinter auction" with 15-second soft end, or "adrenalin auction" where the soft end starts at the value of 30 seconds but after every 1000 bids is lowered by 5 seconds (up to 10 seconds).

7 We may fairly suppose that online auction users are experienced online shoppers as well. That is probably why Bonus.cz does not put its reputation at risk by exaggerating its price suggestions. 
these auctions finished within the first 100 bids. On the contrary, about $20 \%$ of auctions lasted longer than 1,000 bids, of which only 32 ran over 10,000 bids. The longest auction lasted 30,155 bids which meant over CZK 150,000 paid for an HTC smart phone worth about CZK 15,000.

Figure 1 shows how many auctions ended at each specific number of bids. Auctions with a price increment of CZK 1 generally lasted a shorter time than auctions with the price increment of CZK 0.1, as more of them ended during the early stage of bidding. On average, the closing prices were about $15 \%$ of SRPs for auctions with a price increment of CZK 1 and $2.4 \%$ for auctions with a price increment of CZK0.1.

Figure 2 shows the comparison of collected revenue with the suggested retail price. The value of $100 \%$ would mean the same revenue as with online retailing, supposing the same demand. Generally, Bonus.cz makes the largest profits on bid packs, toys and cell phones. Bonus.cz collects $115 \%$ of the suggested retail price from their auctions on average. This means an extra profit of $15 \%$ above the price they could obtain by retailing, supposing the same demand.

\section{Evidence for the Model}

In this section, we test whether the symmetric model for pay-per-bid auctions can explain the distribution of ended auctions on Bonus.cz. We use the Pearson's chi-square goodness-of-fit test to compare observed frequencies $O_{i}$ with expected frequencies $E_{i}$. We will give a brief overview of the test, a complete treatment can be found in Cameron and Trivedi (2005). The null hypothesis is that the observed frequencies, which are independent, come from the correct distribution. The test statistic is:

$$
\chi^{2}=\sum_{i=1}^{n} \frac{\left(O_{i}-E_{i}\right)^{2}}{E_{i}} .
$$

The test statistic is asymptotically $\chi^{2}$ distributed with (n-1) degrees of freedom. If the test statistic exceeds the tabulated critical value, we reject the null hypothesis that the observed frequencies come from the proposed distribution.

The graphs in Figure 3 give a visual illustration how the observed data match the theoretical distribution. We are giving two examples of auctions that ran on Bonus.cz. The first one shows an auction for a 50 bids pack. These auctions generate a lot of attention and last generally longer than is the equilibrium prediction. The latter shows an auction for The Sims PC game where the theoretical distribution roughly matches the observed frequencies. For each interval, the height of the column shows a share of auctions that ended with a certain number of bids. The continuous line represents the probability density function predicted by the model.

We tested 64 items that increased by CZK1 and 70 items that increased by CZK 0.1 . We substituted the suggested retail price for the value of an item (for the reasons mentioned 
above) and determined the bid fee equal to CZK $5.20^{8}$. We decided to test all subsets with at least 20 unique auctions with a specific price increment because using a stricter limit would significantly decrease variety.

We did not reject the null hypothesis at $5 \%$ significance level for 112 data subsets out of 134, which means that we did not reject the null hypothesis for 4,125 $(69 \%)$ of all 5,976 tested auctions. In Table 1 we show all results of our analysis for each data subset separately. The largest difference between observed and predicted frequencies is for auctions for bid packs, electronics, and surprisingly children toys, where more aggressive bidding occurs.

Figure 1

\section{Distribution of Ended Auctions according to the Number of Placed Bids and the Price Increment}

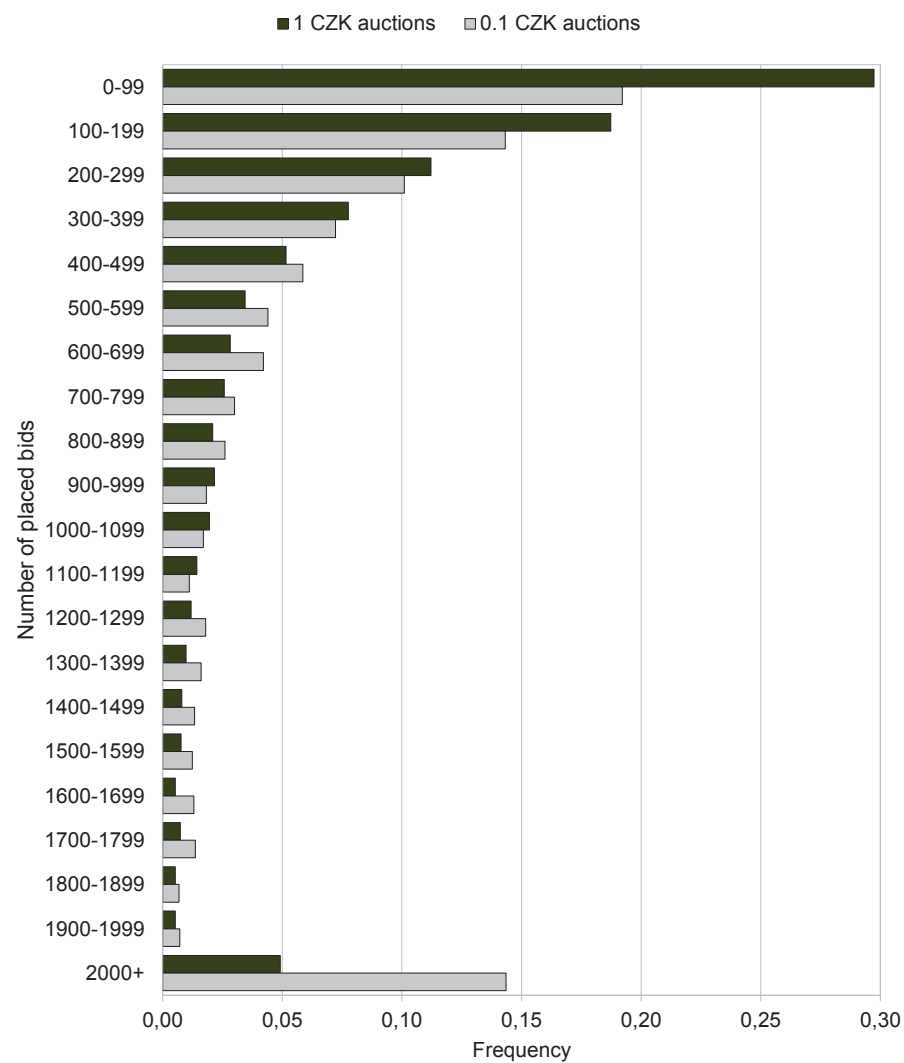

Notes: Black bars show number of ended auctions with the price increment CZK1 as a fraction of all CZK1 auctions. Grey bars show the same for 0.1 auctions.

8 One bid costs CZK 8. However, the price for newcomers is lower, and other bidders may purchase discounted bid packs. Thus the average price of one bid is lower than CZK 8. We used the average price provided us by the company operating Bonus.cz. 
Figure 2

Average Collected Revenue from Auctioning Each Item as a Fraction of the Suggested Retail Price

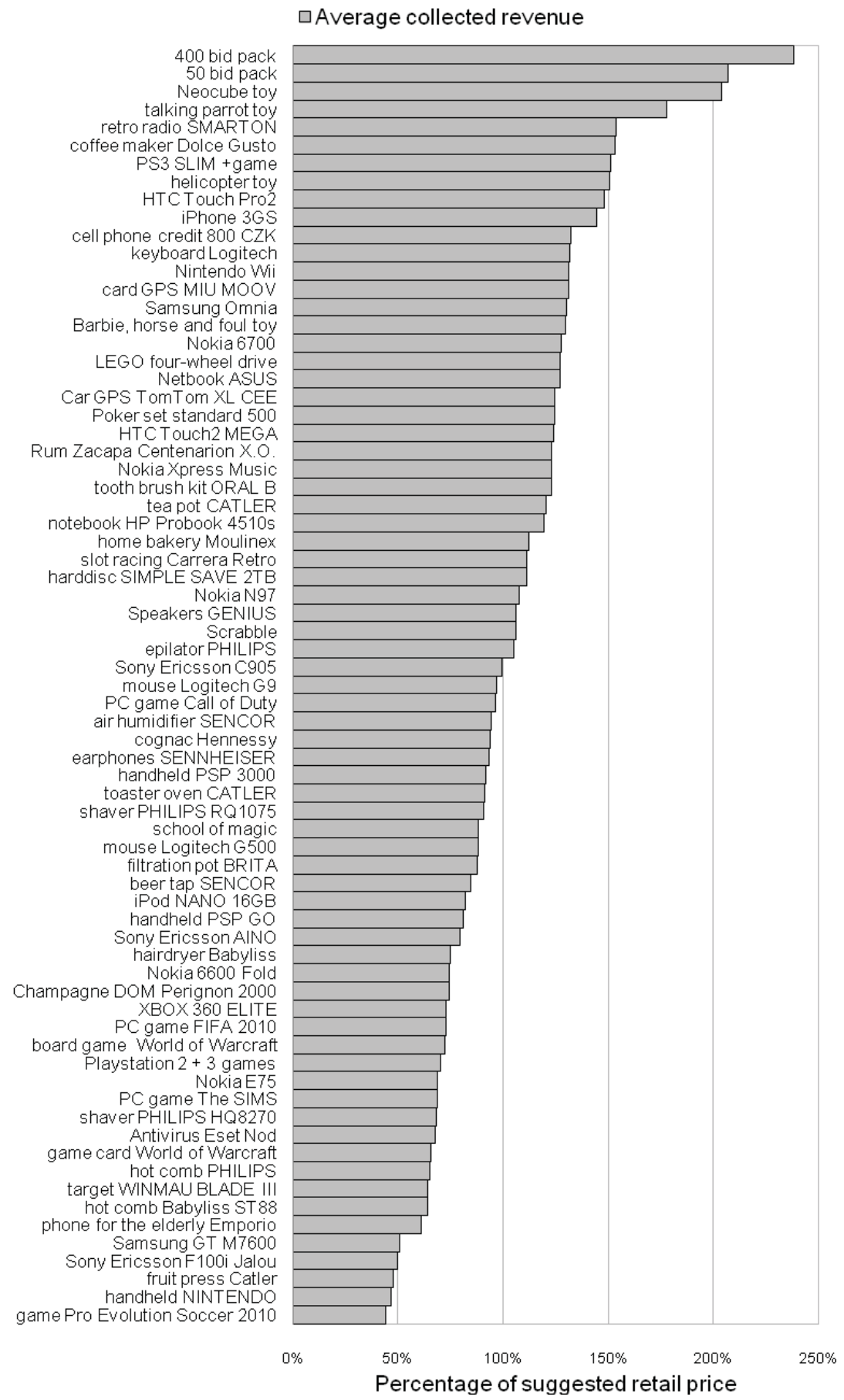




\section{Figure 3}

\section{Comparison of Theoretical and Observed Distribution of Ending Bid for Selected Items}

\section{Auction for 50 bid pack}

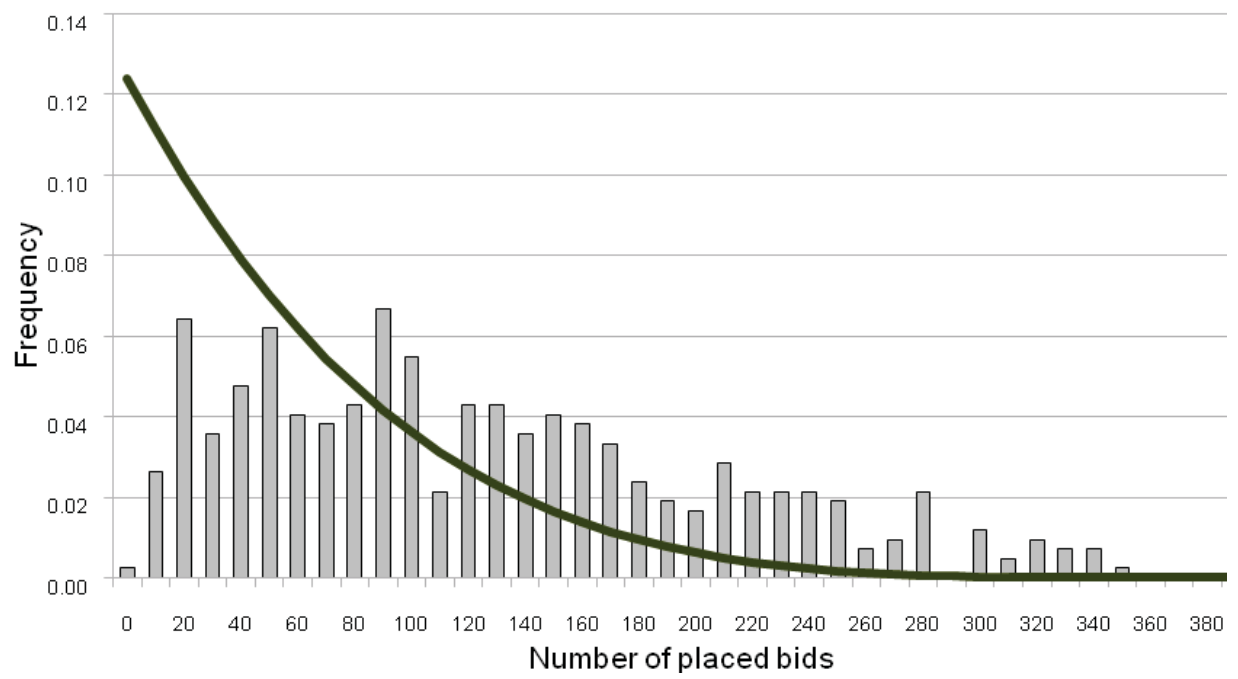

Auction for a PC game The Sims

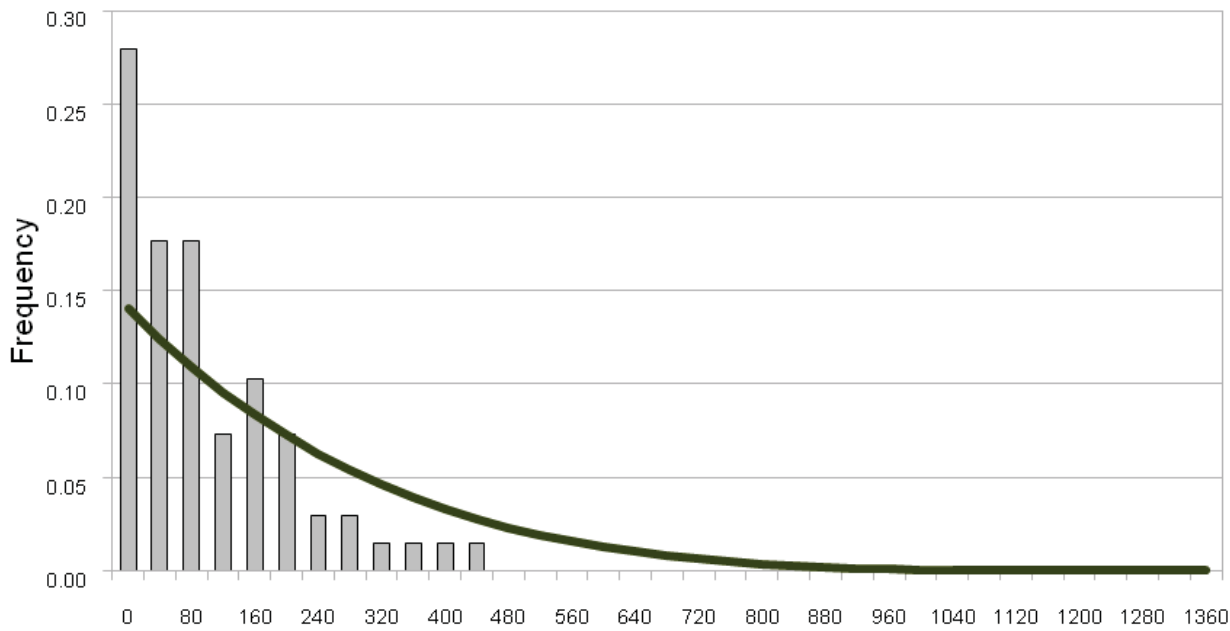

Notes: X-axis shows the number of bids at which an auction terminated. Y-axis shows the number of auctions ended as a fraction of all observed auctions for such item. Grey bars denote observed auctions as a fraction of all auctions for the same item. The black line represents the probability density function. 
Table 1

Pearson Chi-Square Goodness-of-Fit Test Results

\begin{tabular}{|c|c|c|c|c|c|c|c|}
\hline Item name & $\begin{array}{l}\text { Price } \\
\text { incre- } \\
\text { ment }\end{array}$ & $\begin{array}{l}\text { Number } \\
\text { of obser- } \\
\text { vations }\end{array}$ & Chi-value & Item name & $\begin{array}{l}\text { Price } \\
\text { incre- } \\
\text { ment }\end{array}$ & $\begin{array}{l}\text { Number } \\
\text { of obser- } \\
\text { vations }\end{array}$ & Chi-value \\
\hline \multirow{2}{*}{ Antivirus Eset Nod } & 0.1 & 27 & 6.16 & \multirow{2}{*}{ Samsung GT M7600 } & 1 & 21 & $7.04^{*}$ \\
\hline & 1 & 25 & $12.81^{* *}$ & & 0.1 & 29 & $14.2^{\star *}$ \\
\hline \multirow{2}{*}{400 bid pack } & 0.1 & 364 & $279.02^{\star \star \star *}$ & \multirow{2}{*}{ Samsung Omnia } & 1 & 25 & 1.00 \\
\hline & 1 & 230 & $38.07^{\star \star \star}$ & & 0.1 & 30 & 1.23 \\
\hline 50 bid pack & 1 & 420 & $333.41^{* * *}$ & \multirow{2}{*}{ Sony Ericsson AINO } & 1 & 21 & 3.43 \\
\hline \multirow{2}{*}{$\begin{array}{l}\text { Slot racing Carrera } \\
\text { Retro }\end{array}$} & 1 & 29 & 8.83 & & 0.1 & 42 & 8.17 \\
\hline & 0.1 & 32 & 7.58 & \multirow{2}{*}{ Sony Ericsson C905 } & 1 & 39 & 6.22 \\
\hline \multirow{2}{*}{$\begin{array}{l}\text { board game World of } \\
\text { Warcraft }\end{array}$} & 1 & 35 & 7.60 & & 0.1 & 49 & 3.05 \\
\hline & 0.1 & 45 & 6.22 & Sony Ericsson F100i & 0.1 & 33 & $14.57^{\star \star}$ \\
\hline \multirow{2}{*}{ Beer tap SENCOR } & 1 & 41 & 2.78 & \multirow{2}{*}{ IPod NANO 16GB } & 1 & 27 & 7.20 \\
\hline & 0.1 & 66 & 9.11 & & 0.1 & 51 & 3.11 \\
\hline \multirow{2}{*}{ Epilator PHILIPS } & 1 & 33 & 1.79 & \multirow{2}{*}{ Mouse Logitech G9 } & 1 & 37 & 1.06 \\
\hline & 0.1 & 49 & 5.26 & & 0.1 & 27 & 5.84 \\
\hline Filtration pot BRITA & 0.1 & 34 & 3.10 & \multirow{2}{*}{ Mouse Logitech G500 } & 1 & 28 & 8.55 \\
\hline \multirow{2}{*}{ Hair dryer Babyliss } & 1 & 29 & 4.90 & & 0.1 & 38 & 4.10 \\
\hline & 0.1 & 33 & 1.11 & \multirow{2}{*}{ Car GPS MIU MOOV } & 1 & 37 & 4.13 \\
\hline \multirow{2}{*}{ Handheld NINTENDO } & 1 & 61 & $25.28^{\star \star *}$ & & 0.1 & 50 & 4.86 \\
\hline & 0.1 & 70 & $44.7^{\star \star \star}$ & \multirow{2}{*}{$\begin{array}{l}\text { Car GPS TomTom } \\
\text { XL CEE }\end{array}$} & 1 & 26 & 5.66 \\
\hline \multirow{2}{*}{ Handheld PSP 3000} & 1 & 27 & 0.14 & & 0.1 & 34 & 8.77 \\
\hline & 0.1 & 36 & 3.62 & & 1 & 38 & 0.98 \\
\hline & 0.1 & 39 & 7.45 & Nintendo Wii & 0.1 & 60 & 4.82 \\
\hline Handheld PSP GO & 1 & 40 & 6.59 & Netbook ASUS & 0.1 & 59 & 4.79 \\
\hline Game card World of & 1 & 95 & $65.51^{\star \star \star}$ & Notebook HP Probook & 1 & 22 & 1.24 \\
\hline Warcraft & 0.1 & 53 & 2.88 & $4510 \mathrm{~s}$ & 0.1 & 28 & 2.22 \\
\hline Shaver PHILIPS & 1 & 30 & 9.14 & & 1 & 30 & 3.99 \\
\hline HQ8270 & 0.1 & 45 & 8.57 & PC Game Call of Duty & 0.1 & 38 & 2.26 \\
\hline Shaver PHILIPS & 1 & 23 & 3.25 & & 1 & 44 & 9.31 \\
\hline RQ1075 & 0.1 & 31 & 1.58 & PC Game FIFA 2010 & 0.1 & 40 & 7.72 \\
\hline Barbie doll, horse & 1 & 23 & 0.88 & & 1 & 68 & $23.69^{* *}$ \\
\hline and foal & 0.1 & 34 & 6.53 & PC Game The SIMS & 0.1 & 68 & 2.39 \\
\hline & 1 & 31 & 3.72 & & 1 & 20 & 1.65 \\
\hline Helicopter toy & 0.1 & 22 & 3.72 & Home bakery MoulInex & 0.1 & 35 & 3.13 \\
\hline & 1 & 38 & $28.89^{\star \star \star}$ & Playstation $2+3$ & 1 & 27 & 7.77 \\
\hline Neocube toy & 0.1 & 26 & $18.08^{\star \star *}$ & games & 0.1 & 35 & 1.90 \\
\hline Game Pro Evolution & 1 & 29 & $13.41^{* *}$ & Poker kit standard 500 & 1 & 45 & 0.86 \\
\hline Soccer 2010 & 0.1 & 26 & $8.65^{\star}$ & Poker kıt standard sou & 0.1 & 66 & 6.44 \\
\hline coffee maker Dolce & 1 & 52 & 6.65 & Harddisc SIMPLE & 1 & 30 & 2.39 \\
\hline Gusto & 0.1 & 58 & $20.95^{\text {** }}$ & SAVE 2TB & 0.1 & 33 & 1.42 \\
\hline & 1 & 22 & 1.91 & & 1 & 37 & 4.28 \\
\hline Keyboard Logitech & 0.1 & 38 & 0.32 & PS3 SLIM + game & 0.1 & 52 & 9.08 \\
\hline & 1 & 23 & 6.41 & & 1 & 26 & 1.13 \\
\hline Cognac Hennessy & 0.1 & 43 & 1.85 & Speaker set GENIUS & 0.1 & 32 & 7.87 \\
\hline Cell phone credit & 1 & 82 & 4.43 & & 1 & 23 & 1.51 \\
\hline CZK800 & 0.1 & 59 & $11.68^{*}$ & Retro radio SMARTON & 0.1 & 41 & $13.24^{* *}$ \\
\hline & 1 & 41 & $29.15^{\text {***}}$ & Rum Zacapa & 1 & 29 & 1.52 \\
\hline Fruit press Catler & 0.1 & 52 & $20.24^{\star *}$ & Centenation X.O. & 0.1 & 39 & 1.38 \\
\hline School of Magic & 1 & 55 & 7.04 & Scrabble & 1 & 52 & 1.27 \\
\hline School of IMlagic & 0.1 & 49 & 7.71 & Scrabble & 0.1 & 50 & 4.96 \\
\hline & 1 & 39 & 6.39 & & 1 & 31 & 7.39 \\
\hline Talking parrot toy & 0.1 & 30 & 4.71 & Perignon 2000 & 0.1 & 40 & 5.59 \\
\hline HTC Touch Pro2 & 0.1 & 54 & 3.35 & Target WINMAU & 1 & 23 & 4.11 \\
\hline & 1 & 22 & 0.29 & BLADE III & 0.1 & 26 & 6.27 \\
\hline HTC Touch2 MEGA & 0.1 & 40 & 2.13 & & 1 & 35 & 2.45 \\
\hline IPhone 3GS & 0.1 & 33 & 1.46 & Toaster oven CATLER & 0.1 & 50 & 1.40 \\
\hline
\end{tabular}




\begin{tabular}{|c|c|c|c|c|c|c|c|}
\hline Nokia 6700 & 0.1 & 35 & 1.24 & \multirow{2}{*}{ Teapot CATLER } & 1 & 48 & 2.58 \\
\hline \multirow{2}{*}{ Nokia E75 } & 1 & 24 & 7.65 & & 0.1 & 64 & 4.76 \\
\hline & 0.1 & 31 & 5.23 & \multirow{2}{*}{ XBOX 360 ELITE } & 1 & 24 & 5.93 \\
\hline \multirow{2}{*}{ Nokia N97 } & 1 & 28 & 0.72 & & 0.1 & 44 & $12.55^{\star}$ \\
\hline & 0.1 & 44 & 1.00 & \multirow{2}{*}{$\begin{array}{l}\text { Earphones } \\
\text { SENNHEISER }\end{array}$} & 1 & 20 & 2.74 \\
\hline \multirow{2}{*}{ Nokia Xpress Music } & 1 & 43 & 2.10 & & 0.1 & 29 & 3.54 \\
\hline & 0.1 & 56 & 3.16 & \multirow{2}{*}{$\begin{array}{l}\text { Air moisturizer } \\
\text { SENCOR }\end{array}$} & 1 & 37 & 4.83 \\
\hline \multirow{2}{*}{ Nokia 6600 Fold } & 1 & 20 & 1.77 & & 0.1 & 44 & 3.44 \\
\hline & 0.1 & 36 & 10.05 & \multirow{2}{*}{$\begin{array}{l}\text { Hot comb Babyliss } \\
\text { ST88 }\end{array}$} & 1 & 21 & $8.43^{*}$ \\
\hline \multirow{2}{*}{$\begin{array}{l}\text { Cell phone for the } \\
\text { elderly Emporio }\end{array}$} & 1 & 25 & 3.50 & & 0.1 & 36 & 3.06 \\
\hline & 0.1 & 31 & 6.45 & \multirow{2}{*}{ Hot comb PHILIPS } & 1 & 27 & 8.30 \\
\hline \multirow[b]{2}{*}{ Lego four-wheel drive } & 1 & 26 & 1.34 & & 0.1 & 42 & 3.77 \\
\hline & 0.1 & 27 & 3.28 & $\begin{array}{l}\text { Tooth brush kit } \\
\text { ORAL B }\end{array}$ & 0.1 & 35 & 1.28 \\
\hline
\end{tabular}

Notes: Table shows results of Pearson Chi-square goodness-of-fit test, separately for each data subset (different item and price increment). ${ }^{* * *},{ }^{* *},{ }^{*}$ indicate significance at the $0.1,1$ and $5 \%$ level, respectively.

\section{Evidence against the Model}

In the previous section, we found that in the same setting the model explains about the same share of auctions as for the data set of Platt et al. (2010). Yet, some real-life bidders use strategies that might not be consistent with the assumption of indifference in all periods of an auction. The most typical example is "mechanical" overbidding immediately after a previous bid has been placed, in order to discourage further bidding. In our opinion, this does not violate the assumptions of the model since no bidder is able to make his bidding threat persistently credible. ${ }^{9}$

However, we find another regularity which contradicts the implications of the mentioned model and is useful in practice. As mentioned earlier, Platt et al. (2010) calculated the expected revenue of a pay-per-bid auction to equal $v-b$, so the generated revenue would be the same irrespective of price increment. Yet, on Bonus.cz, some auctions were with price increment of CZK 1, some CZK 0.1 and only recently CZK0.01. On Swoopo.com, the majority of auctions used to increase by $\notin 15$ with each bid, but at present, most of them are penny auctions i.e. have price increment of $\phi 1 .{ }^{10}$ Why do auctioneers shift to auctions with lower price increments? We found that their efforts may not be strictly motivated by product differentiation but that there may be financial incentives as well.

If we divide our data set into groups based on price increment, we calculate that the average collected revenue for CZK 1 auctions is only $95 \%$ of their suggested retail price (SRP). However, CZK 0.1 auctions deliver revenue equal to $130 \%$ of the SRP on average. Given that these averages are calculated over samples of about 3,000 auctions each, it is obvious that difference is not purely random.

This result is not without exception. Figure 4 shows the collected revenue as a percentage of the SRP, drawing a distinction between price increments. All auctions over $100 \%$

9 Recently, Bonus.cz started a novelty: "anonymous auctions". Contrary to regular auctions, where 10 last bidders are listed, here only the list of $5^{\text {th }}$ to $10^{\text {th }}$ bidder is published. Efficiency of the frequent aggressive-bidding strategy is weakened. Therefore, this auction format may be helpful in further assessing the influence of aggressive bidding on the average collected revenue.

10 In the past, there were also fixed price auctions, but they were discontinued due to their alleged resemblance to lottery. 
delivered more revenue than could be obtained through retailing, given the same demand. More than $20 \%$ of all auctions of both types generated less than $25 \%$ in revenue compared to SRP, with almost $60 \%$ of auctions delivering an overall loss. Yet, what accounts for the high averages are auctions that run for a long time and generate multiples of the SRP. As we see from the graph, more auctions with the price increment CZK0.1 generate extraordinarily large revenues. Over 7\% of CZK 0.1 auctions generate more than four times the opportunity cost of retailing, compared to only $2 \%$ of CZK 1 auctions.

Figure 4

Collected Revenue as a Fraction of a Suggested Retail Price

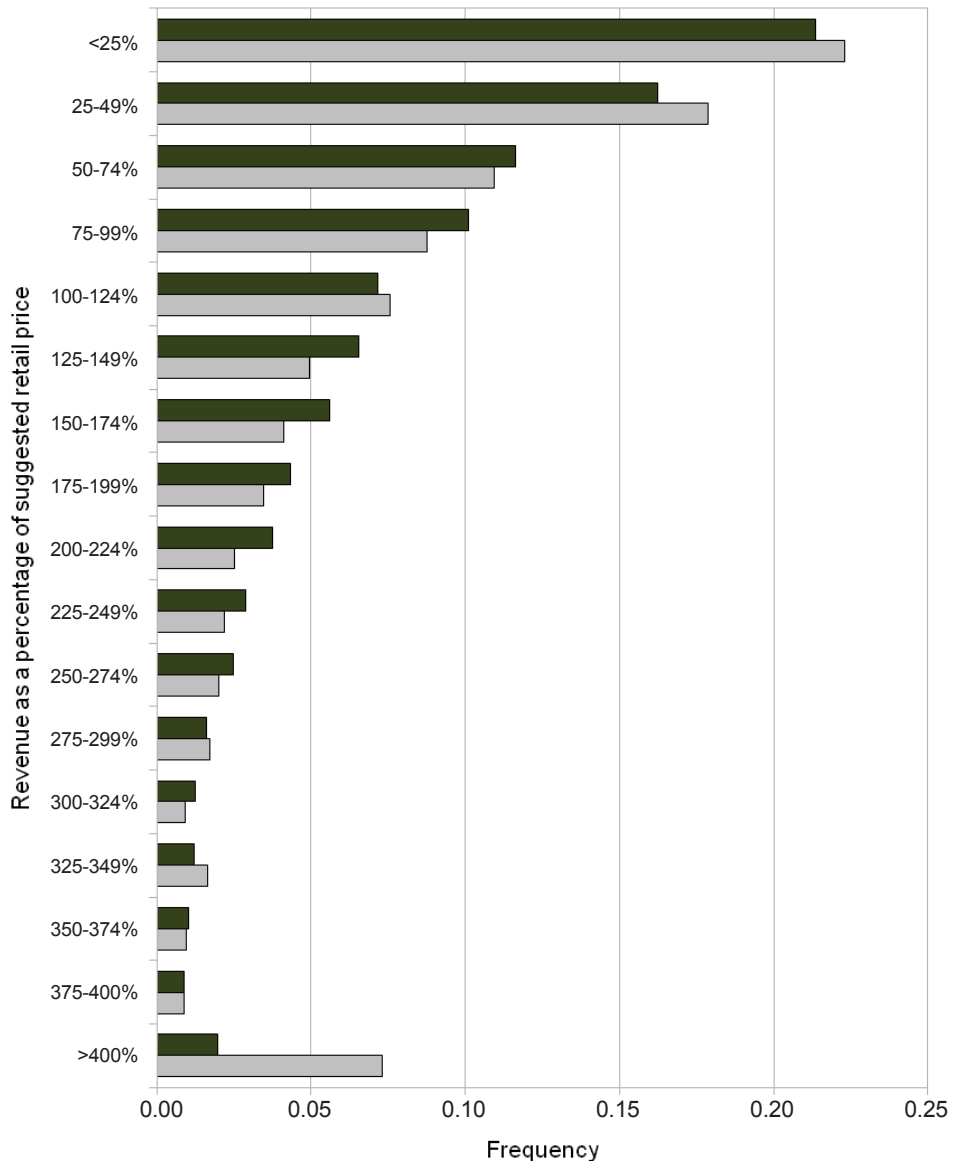

-1 CZK auctions

$\square 0.1$ CZK auctions
Notes: Vertical axis shows intervals for the revenue as a percentage of price. Horizontal axis shows the number of auctions as a fraction of all auctions. Black bars denote auctions with the price increment 1 CZK, grey bars show the same for $0.1 \mathrm{CZK}$ auctions.

These findings cannot be explained by different preferences of bidders toward risk, because both types of auctions would be affected in a similar manner. The same holds for sunk cost fallacy. We suggest that it is skewness in payoffs ${ }^{11}$ that counts for the discrepancy. As

11 Platt et al. (2010) mention the term. Nevertheless, they do not use it to explain the discrepancy, since their dataset contains auctions with only one price increment. 
Golec and Tamarkin (1998) show for horse-track betting and as Garret and Sobel (1999) show for lottery games, gamblers may be risk averse, and still attend a lottery, i.e. wager disproportionally more on low-probability, high-variance options than on high-probability, low-variance ones. Their utility does not come from variance of payoffs but from the asymmetry of payoff distribution. ${ }^{12}$ In case of pay-per-bid auctions, this translates into bidders favouring participation in auctions in which they can potentially win more at low probabilities rather than bidding in auctions where the gain is small but more probable. This is consistent with observing very few auctions' final prices near their SRPs. If we recall our example from Section 2, placing $392^{\text {nd }}$ bid guarantees winning with certainty but the bidder only recoups his costs, hence is not likely to bid. When a user weighs his bidding options, he is already sure how many bids have been placed on each specific auction, so he considers only the objective probability that an auction ends after his bid, $1-\mu_{q+l}$, which is equal to $1-\frac{b}{v-s \cdot(q-1)}$. This function is increasing in the number of already placed bids and in the price increment. If we consider two identical auctions except for their price increment, it is obvious that one bid in a CZK1 auction would cause the same increase in probability that the auction ends, as 10 bids in CZK 0.1 auction. The potential gain from winning shrinks quicker as well. If bidders prefer skewness in payoffs, auctions with higher price increment cease to be attractive to users with fewer bids. Therefore they generate less revenue because most revenue comes from bid fees rather than final prices.

This explanation seems very plausible. Should there be any utility tied with the imagination of victory (before attending a game), it should be correlated to the size of the prize; on the other hand, the intensity of our visualizations depends more on different aspects than on the probability of different faces of affaires. The prize in our case is a purchase of an item for only a fraction of its retail price. This fact creates also an additional momentum compared to lotteries. The result in a lottery is given by pure luck; on the other hand, one may present his auction victory as a skill of clever-buying, which should raise his value in the eyes of others.

When designing a pay-per-bid auction, one should realize that the lower the price increment is, the lower the closing price on average is, and the bigger the prize is for the winner. Thus the auctions with lower price increments shall be preferred. These findings are strongly supported by reality. In April 2010, Bonus.cz introduced auctions with a price increment CZK 0.01, and in 2011 almost all auctions increased by CZK 0.01, with only a fraction of them being CZK 0.1 and no CZK 1 auctions.

\section{Conclusion}

In this paper we tested whether the symmetric model for pay-per-bid auctions suggested by Platt et al. (2010) is capable of explaining the bidding we observed at the Czech auction site Bonus.cz. In sub-game perfect Nash equilibrium of the model, all potential bidders are indifferent about bidding in each period of every auction. The observed reality is slightly different as users adopt bidding strategies such as aggressive bidding. The goal is to signal

12 This can be measured by skewness, the third standardized moment of payoff distribution around mean. 
that the bidder is not indifferent about bidding. Fortunately, verbal communication between bidders cannot occur so the credibility of these threats is always only temporary. Therefore, bidding strategies do not have to play a role in overall auction results.

Using the model, we analysed over 6,000 ended auctions that ran on Bonus.cz. We supposed that potential bidders are risk neutral and we used CZK5.20 as the bid fee. With the use of the Pearson Chi-square test we found out that for $69 \%$ of auctioned items on Bonus.cz the calculated probabilities matched our observed data at 5\% significance level. The results are similar to those of Platt et al. (2010).

On the other hand, the model suggested by Platt et al. (2010) is not able to capture a discrepancy between auctions with different price increments. For all of them, it predicts the same profit margins. On the contrary, according to our observed data, auctions with a price increment of CZK 1 on average generated revenue equal to $95 \%$ of the suggested retail price while auctions increasing with each bid by CZK0.1 on average generated revenue equal to $130 \%$ of the suggested retail price. We suggest that pay-per-bid auction users have preferences for skewness in payoff distribution, $i$ e. they may prefer unfair bets if the payoff is high enough, even if they are risk averse.

\section{References}

Augenblick, N. (2009), "Consumer and Producer Behavior in the Market for Penny Auctions: A Theoretical and Empirical Analysis." Unpublished manuscript, available at http://www.stanford. edu/ ned789/Augenblick_JMP_Penny_Auction.pdf.

Baye, M. R., Kovenock, D., Vries, C. G. (1996), "The All-Pay Auction with Complete Information." Economic Theory, 8 (2): pp. 291-305.

Byers, J. W., Mitzenmacher, M., Zervas, G. (2010), "Information Asymmetries in Pay-per-Bid Auctions." In Proceedings of the 11th ACM conference on Electronic commerce. Cambridge, Massachusetts, USA: ACM, pp. 1-12.

Cameron, A. C., Trivedi, P. K. (2005), Microeconometrics, New York: Cambridge University Press.

Garrett, T. A., Sobel, R. S. (1999), "Gamblers Favor Skewness, not Risk: Further Evidence from United States' Lottery Games." Economics Letters, 63 (1): pp. 85-90.

Golec, J., Tamarkin, M. (1998), "Bettors Love Skewness, Not Risk, at the Horse Track." The Journal of Political Economy, 106 (1): pp. 205-225.

Hinnosaar, T. (2009), "Penny Auctions." Unpublished manuscript, available at http://toomas. hinnosaar.net.

Maynard Smith, J. (1974), "The Theory of Games and the Evolution of Animal Conflicts." Journal of Theoretical Biology, 47 (1): pp. 209-221.

Platt, B. C., Price, J., Tappen, H. (2010), "Pay-to-Bid Auctions." National Bureau of Economic Research Working Paper Series, No. 15695.

Shubik, M. (1971), "The Dollar Auction Game: A Paradox in Non-cooperative Behavior and Escalation." The Journal of Conflict Resolution, 15 (1): pp. 109-111.

Zandl, P. (2009), “Přicházejí: aukce s platbou za přihoz, letadlo či spíše loterie?” Retrieved February 15, 2011, from http://www.lupa.cz/clanky/prichazeji-aukce-s-platbou-za-prihoz/. 